\title{
Computation on Bus Delay at Stops in Beijing through Statistical Analysis
}

\author{
Shaokuan Chen, ${ }^{1,2}$ Rui Zhou, ${ }^{1}$ Yangfan Zhou, ${ }^{1}$ and Baohua Mao ${ }^{1,2}$ \\ ${ }^{1}$ The MOE Key Laboratory for Transportation Complex Systems Theory and Technology, School of Traffic \& Transportation, \\ Beijing Jiaotong University, Beijing 100044, China \\ ${ }^{2}$ Integrated Transport Research Centre of China, Beijing Jiaotong University, Beijing 100044, China
}

Correspondence should be addressed to Shaokuan Chen; shkchen@bjtu.edu.cn

Received 6 February 2013; Accepted 30 March 2013

Academic Editor: Dan Simon

Copyright (C) 2013 Shaokuan Chen et al. This is an open access article distributed under the Creative Commons Attribution License, which permits unrestricted use, distribution, and reproduction in any medium, provided the original work is properly cited.

\begin{abstract}
Delays at bus stops have seriously affected the efficiency of bus operation and the improvement of level of services of public transportation and greatly influenced the preferences of passengers to choose bus services. In this paper, the analysis on arriving, dwell and leaving process of buses and the method to calculate bus delays at stops are proposed according to survey data from three bus routes in Beijing. Statistical analysis is then adopted respectively to evaluate average times that buses are docking at curbside and bay-style stops. Moreover, it is noted that different load factors of passengers in buses have significantly influenced the average boarding and alighting time per person. The effectiveness and accuracy of the proposed methods is illustrated through case studies. This study is crucial and helpful for the planners and operators to evaluate the efficiency and level of service of urban public transportation.
\end{abstract}

\section{Introduction}

The priority of bus transportation is a crucial way to mitigate the severe traffic congestions in large cities, such as Beijing and London. The proportion of passenger by buses has increased to forty percent in Beijing since the policy of bus priority was launched in 2007 while the overall operational speed of buses has been gradually decreased to $22 \mathrm{~km} / \mathrm{h}$ during peak hour [1].

Bus delay at stops due to different cause factors leads to a distinct drop of bus travel efficiency. Research on the interactions between buses, passengers and delays at bus stops is dramatically important to evaluate the performances of bus operation and improve the design of infrastructure [2]. For example, the average times of passengers walking along the stops with a long platform, especially for BRT (Bus Rapid Transit) stops, can be nearly 10 times more than those of other stops [3]. The requirement of walking to the bus door may lead to a higher bus dwell time.

Researchers have developed some significant works on bus dwell time and delay at stops. The improvements of bus stop location, near or far from intersections, and its grade allow buses the better services for passengers through the reductions of delay at stops [4]. Bus stop times could be expressed as linear functions of numbers of passengers boarding and alighting, with coefficients varying between different bus types, and fare collection systems (passenger payment through paper tickets on or outside the vehicle and electronic cards at the entrance of the vehicle) $[5,6]$, however they did not discriminate whether buses are crowded or not. There is a research denoting that automatic fare systems are estimated to bring a $1.5 \mathrm{~s}$ improvement on boarding and alighting time only on uncrowded buses [6]. A bus dwelltime model by a statistical evaluation of boarding with high passenger demand at stops also was proposed and its result was different from the generally accepted linear model [7].

The countermeasures to reduce delays at stops are provided with the analysis and development on the number of boarding and alighting passengers, degree of congestion in buses [8], ways of passenger disembarking [9], platform height and door width [10] and layouts of bus stops, such as curbside or bay-style [11]. The existing research indicates that 
bus dwell times and average passenger boarding and alighting times at stops can be explained using descriptive statistics [12].

This study employs statistical methods to evaluate average times that buses are docking at curbside and bay-style stops according to real collected data in Beijing by considering the arriving, dwell and leaving process of buses. Load factors of passengers in buses are also considered in the analysis on the boarding and alighting time of passengers. The adaptability of the delay calculation is given in case studies.

The remainder of this paper is organized as follows. Section 2 gives a common delay analysis of buses at stops. Section 3 illustrates bus delay composition at stops and its measurement. Section 4 proposes the calculation method on bus delay. Section 5 validates the proposed delay calculation method based on field data through case studies and Section 6 draws the conclusions.

\section{Delay Analysis at Bus Stops}

The docking process while a bus is approaching a stop and then leaving it can be divided into three stages: arriving and decelerating before stopping $\rightarrow$ dwelling at stops $\rightarrow$ acceleration and leaving after stopping. The relationship between travel distance and time during the docking process is illustrated in Figure 1. Delays at bus stops, which are commonly defined as the additional time from the docking of buses more than the expected operation time, will also be divided into the three stages.

2.1. Arriving and Decelerating. The first stage of docking process refers that buses begin to decelerate at the distance $L_{1}$ away from stops and then stop after the duration time $T_{1}$. During this process, delays may often occur if many buses are in queue, hindered and even blocked each other due to insufficient dwell space. Some conflicts and disturbances, such as those from bicycles and pedestrians within docking areas, also cause buses to constantly decelerate and then slightly accelerate before stopping and bring obvious delays. Moreover, these delays will probably be propagated in the form of waves to those buses which closely follows, leading to more extra waiting time [13].

2.2. Dwelling. The second stage, dwelling, involves dooropen, boarding and alighting of passengers and door-close when buses are dwelling at stops. The dwell time is expressed as $T_{2}$ shown in Figure 1. The door-open and door-close times which mainly depend on the electromechanical performance of relative equipments are usually a tiny contribution of dwell time, for instance usually one to three seconds [8], and insensitive to the number of passengers boarding and alighting. The boarding and alighting time of passengers is closely related to the number of passengers and is also often influenced by the load factor of buses [14] and the characteristics of passengers. The dwell delay is usually calculated by an equation of the number of passengers [6].

2.3. Accelerating and Leaving. The last stage of docking process illustrates that buses accelerate and leave from bus stops after boarding and alighting passengers. The stage covers the travel distance of buses $L_{2}$ within the duration $T_{3}$ as shown in Figure 1. Similar to the first stage, the delay during this stage will emerge if buses merge, weave and even overtake each other or they are obstructed by pedestrians and bicycles.

2.4. Influencing Factors. The delay at bus stops is influenced by many factors in different aspects, including passengers, buses, stops and their surrounding traffic conditions.

(i) Passengers: The attributes of passengers have obvious effects on bus running time [15] and delay at stops. They refer to the age and gender of passengers, health, the number and size of luggage and payment ways [10]. Furthermore, discontinuous passenger flow also greatly increases bus delay.

(ii) Bus vehicles: The good performances of vehicle may reduce bus delay at stops, such as high traction and braking force. The capacity and arriving rate of bus, the number and width of door, the height of floor as well as the load factor of passengers are important contributions influencing bus delay.

(iii) Stops: The characteristics of bus stop, including their length, waiting area, berth number, influence the whole process when buses are docking at stops. The utilization of bus stops decrease with the increasing number of berth.

(iv) Surrounding traffic conditions: Bus stops mostly neighboring urban roads and buses are easily mixed in heavy traffic flow. Additional delays can be produced due to traffic conditions on roads, such as overlarge traffic flow and interference between buses and other vehicles, pedestrians.

\section{Delay Composition and Its Measurement}

3.1. Delay Composition. The delay at bus stops includes several components that can be summarized as time lost while a bus is stopped (for doors to open and close, for passengers to board and alight) and time lost during deceleration and acceleration [4]. Delay is usually split into two parts, control delay and additional delay. The former is mainly caused by signal control and some infrastructures and the latter refers to some uncertain elements [16]. The additional delay has more obvious influences on the total delay at bus stops. It always shows the characteristics hard to identify and measure and is probably caused by the following reasons.

(i) Queuing delay: If there is not enough space within stopping area, buses have to queue nearby for a period of time.

(ii) Hindered delay: Buses will be hindered by other buses, bicycles and pedestrians when they are arriving at or leaving bus stops.

(iii) Waiting delay: Buses sometimes have to wait for the passengers boarding or alighting slowly at bus stops. 


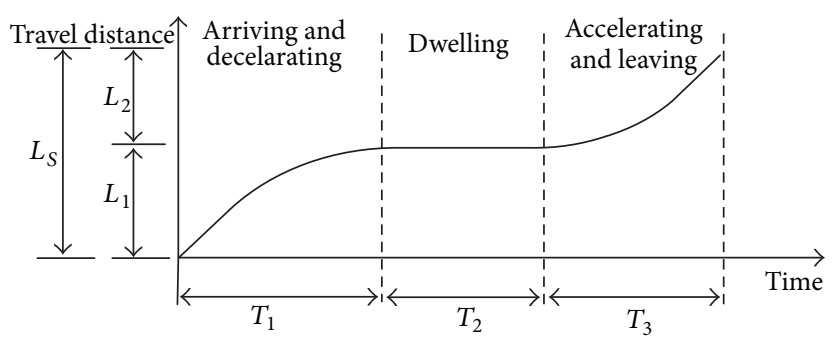

FIGURE 1: Time-position diagram through bus stops.

(iv) Second-stop delay: Buses stop twice or more at bus stops over arriving or leaving for some reasons, such as accidents and mechanical failures.

(v) Other delay: Bus delay is caused by other reasons which are not involved in the former four sections, such as those delays caused by inappropriate bus departing interval [17].

3.2. Measurement. The delay at bus stops is calculated according to the difference between the actual and expected operation times. The actual operation time is lasting from arriving and decelerating to accelerating and leaving of buses in practice, that is, the sum of $T_{1}, T_{2}$ and $T_{3}$. The expected operation time indicates the operation duration of buses under ideal conditions. For example, boarding and alighting of passengers at bus stops are unhindered and uninterrupted. The delay can be simply expressed and computed by (1)

$$
T_{d}=T_{1}+T_{2}+T_{3}-T_{1}^{*}-T_{3}^{*}-\lambda \cdot \max \left(m_{1}, \ldots, m_{i}\right),
$$

where $T_{d}$ denotes the total delay when buses are docking at stops, $s ; T_{1}$ denotes the actual arriving and decelerating time of buses approaching stops, $s ; T_{2}$ denotes the actual dwelling time of buses at stops, $s ; T_{3}$ denotes the actual accelerating and leaving time of buses from stops, $s$; $T_{1}^{*}$ denotes the expected arriving and decelerating time of buses approaching stops, $s ; T_{3}^{*}$ denotes the expected accelerating and leaving time of buses from stops, $s ; \lambda$ denotes the average time per passenger when boarding and alighting, $s /$ per; $m_{i}$ denotes the number of passengers boarding and alighting at door $i$, person.

The time of door-open and door-close is commonly converted into the boarding and alighting time of passengers as it is a comparatively tiny and fixed contribution in dwell time.

\section{Calculation on Bus Delay at Stops}

The calculation on bus delay need to carefully consider the actual arriving and leaving time of buses, the actual boarding and alighting time of passengers, involving the time of dooropen and door-close, in light of (1). The data collection is necessary to estimate some key parameters before calculating delays.
4.1. Data Collection. Three bus routes 105, 615 and 919 are selected to collect on-spot data from the public transport network in Beijing. The detailed information of these bus routes are listed in Table 1.

The data collectors divided into two groups complete the collection of required data on twelve buses over the whole operations at morning rush hours (7:00-9:00) and noon hours (12:00-14:00) on January 12 (Wednesday) and 13 (Thursday), 2011. The data over nine buses is employed for delay analysis and the rest data is used for testing the results. The requirements of data collection are illustrated as follow.

(i) Data collections are divided into two categories: one contains on-spot data from curbside stops and the other from bay-style stops.

(ii) The influence scope of stops where buses are arriving and leaving covers overall platforms and sometimes even partial outside area as shown in Figure 2 according to Beijing Standards Design Code of Bus Stops and Stations (DB11/T 715-2010). From Figure 2, the two ends of curbside stops respectively extend outward fifteen and twenty meters for arriving deceleration and leaving acceleration.

(iii) The actual operation time of buses at stops, $T_{1}+T_{2}+T_{3}$, is obtained according to the total time when buses are running through the influence scope of stops.

(iv) Arriving, door-open, dwell, door-close and leaving time of buses are recorded by one group of data collectors on the platforms of bus stops.

(v) The number of passengers in buses and boarding and alighting at every door is collected by the other group of data collectors on board.

(vi) The causes of delay are divided into five groups as depicted in the former section.

4.2. Causes and Distribution of Delay. The data collections are composed of 163 samples on curbside stops and 125 samples on bay-style stops in the on-spot survey. The collected data, including actual docking time and delay occurrence frequency on bus stops, are separately recorded according to the different reasons. 
TABLE 1: Detailed information of selected bus routes.

\begin{tabular}{lcccl}
\hline No. of Route & Bus length (meters) & Number of door & Capacity (persons) & Rules on boarding and alighting \\
\hline 651 & 18 & 3 & 130 & Boarding at middle door, alighting at front and rear doors \\
105 & 12 & 2 & 77 & Boarding at front door, alighting at rear door \\
919 & 10 & 2 & 55 & Boarding at front door, alighting at rear door \\
\hline
\end{tabular}

There are totally 59 and 50 delay samples, which are caused by the five reasons as mentioned before, respectively observed at curbside and bay-style stops. The details on delay reasons and their distributions are summarized in Table 2.

The proportion of queuing delay on curbside stops is $4.37 \%$ lower than that on bay-style stops from Table 2. More than thirty buses on curbside stops are delayed by two reasons at least while twenty seven buses on bay-style stops are delayed. The queuing of buses is the most major reason to cause delay wherever curbside or bay-style stops, which accounts for $59.6 \%$ of the total delay reasons. The second major reason to cause delay is hindered delay by pedestrians, bicycles and other vehicles, covering $37.6 \%$ of the total delay frequency.

4.3. Arriving and Leaving Time of Buses. Arriving and leaving times of buses at stops, $T_{1}$ and $T_{3}$, are usually influenced by road conditions, vehicle performances, traffic flow and the layouts of bus stops [18]. The distributions of these two times at curbside and bay-style stops show different statistics as described in Figures 3 and 4.

The difference of the times $T_{1}$ and $T_{3}$ at curbside stops, whose average values are 9.74 and 10.2 seconds, is not obvious from Figure 3 . The deviations of these time distributions are respectively 2.65 and 4.14 seconds. The average value of $T_{1}$ at bay-style stops is apparently smaller than that of $T_{3}$ from Figure 4 . The average time of 10.11 and 11.12 seconds are also larger than those at curbside stops, whose deviations are 2.85 and 4.82 seconds. The above results indicate two conclusions: first, buses leave from bay-style stops slightly more slowly than those from curbside stops; second, buses leave from stops more slowly than they arrive, no matter curbside or baystyle stops.

4.4. Boarding and Alighting Time of Passengers. The boarding and alighting time of passengers, $T_{a \& b}$, are mainly influenced by passenger number, different layouts of bus stops, docking modes, traffic performances near bus stops and so on. Among these factors, the number of passengers is the most key factor to decide boarding and alighting times. Moreover, the extent of loading passengers in a bus, load factor LF, usually calculated through the ratio of passenger number to bus capacity, evidently affects the estimated results on boarding and alighting time.

The boarding and alighting time per passenger is also investigated and analyzed after on-spot collections. The relationship between average boarding and alighting time and load factor are also given through fitting actual data. The detailed results on the estimation are listed in Table 3 and their scattered data and fitting curves are shown in Figures 5 and 6.

From Table 3, the results of correlation coefficients indicate that exponential distribution is more suitable to fit the relationship between average boarding and alighting time and load factor. For both curbside and bay-style stops, the fitting exponential equations in Table 3 are adopted in the analysis on the passenger number as well boarding and alighting time.

The differences of $T_{a \& b}$ when LF changes are both found for curbside and bay-style stops from Figures 5 and 6 . The variance of $T_{a \& b}$ is not obvious when LF lies within the interval of a small value according to the two figures. For curbside stops, LF is 0.55 when the average boarding and alighting time, $T_{a \& b}, 2.47$ seconds, is input into the fitting exponential equation. The average boarding and alighting times, $T_{a \& b}$, are respectively 2.07 and 3.19 seconds and show apparent differences while LF is separated into two groups by 0.55 . Similar to curbside stops, the average boarding and alighting times at bay-style stops also can also be classified into two groups and are 2.46 and 3.62 seconds respectively when LF is 0.7.

The two groups of $T_{a \& b}$ due to different load factors actually indicate that the full-load extent of passengers in buses greatly influences the boarding and alighting of passengers. Lower load factor, less than 0.55 and 0.7 respectively at curbside and bay-style stops leads to a faster boarding and alighting process as the congestion and obstruction among passengers are relatively smaller. The average boarding and alighting times, $T_{a \& b}$, under higher load factors are 1.54 and 1.47 times of those under lower load factors at both kinds of stop.

To give the practical meaning from the viewpoint of transportation, the estimations on the relationships between the dwelling time and the number passengers boarding and alighting at curbside and bay-style stops are also separated into two groups in light of the value of load factors. The dwell time here includes $T_{a \& b}$ and door-open and-close times unchangeable with the number of passengers. Figures 7, 8, 9 and 10 give the final fitting results on the above relationships.

From Figures 7, 8, 9, and 10, good linear relationships between the dwell time and number of passengers boarding and alighting at both curbside and bay-style stops no matter how much LF (Load factor) is. The slopes of fitting linear functions reveal the average dwell time per passenger when buses are docking at stops and their intercepts are directly associated with the door-open and -close times.

4.5. Delay Calculation at Bus Stops. The dwell time of buses at stops involves three parts as described in the former section. 
TABLE 2: Causes and distributions of delay at curbside and bay-style stops.

\begin{tabular}{lcccc}
\hline Causes & \multicolumn{2}{c}{ Curbside stops } & \multicolumn{2}{c}{ Bay-style stops } \\
& $\begin{array}{c}\text { Frequency of delayed } \\
\text { buses }\end{array}$ & $\begin{array}{c}\text { Proportion accounting } \\
\text { for all delayed buses (\%) }\end{array}$ & $\begin{array}{c}\text { Frequency of delayed } \\
\text { buses }\end{array}$ & $\begin{array}{c}\text { Proportion accounting } \\
\text { for all delayed buses (\%) }\end{array}$ \\
\hline Queuing delay & 34 & 57.63 & 31 & 62.00 \\
Hindered delay & 24 & 40.68 & 17 & 34.00 \\
Waiting delay & 21 & 35.59 & 13 & 26.00 \\
Second-stop delay & 8 & 13.56 & 11 & 22.00 \\
Other delay & 2 & 3.39 & 5 & 10.00 \\
\hline By two reasons at least & 19 & 32.20 & 12 & 24.00 \\
\hline
\end{tabular}
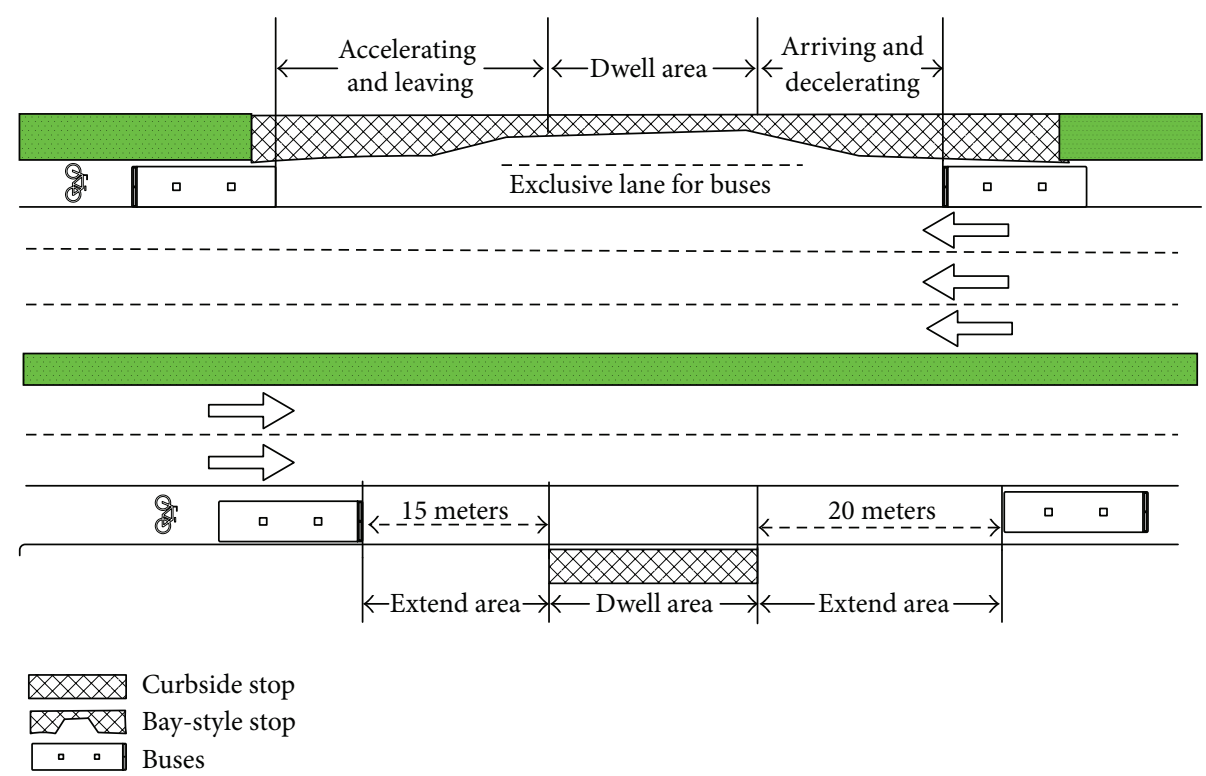

FIgURE 2: Layouts of curbside and bay-style stops.

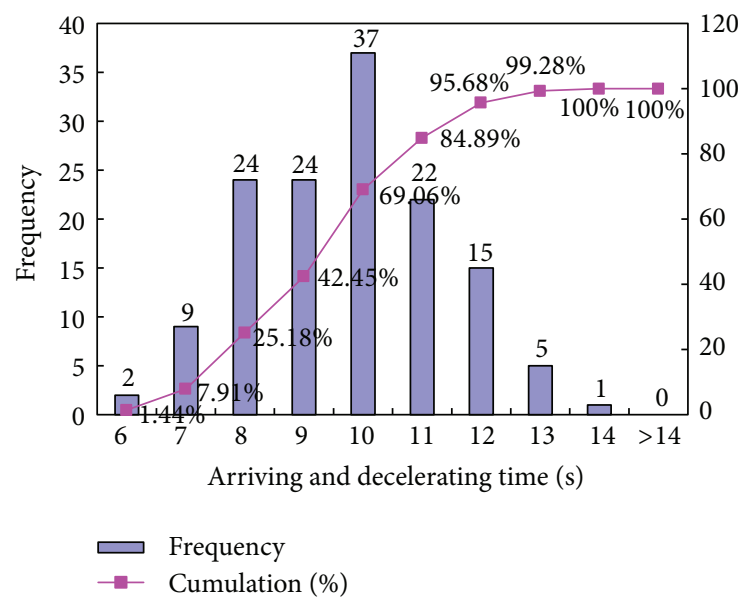

(a)

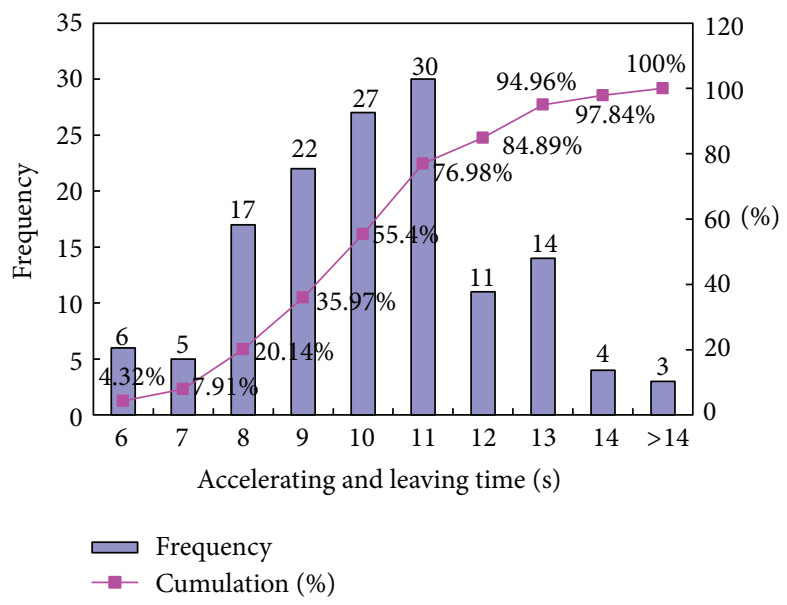

(b)

FIgURE 3: Distribution of $T_{1}$ and $T_{3}$ of buses at curbside stops. 


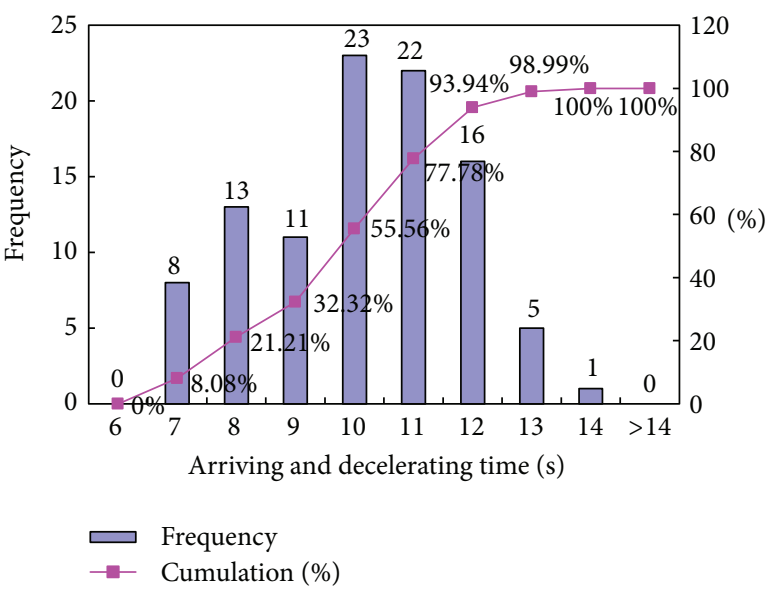

(a)

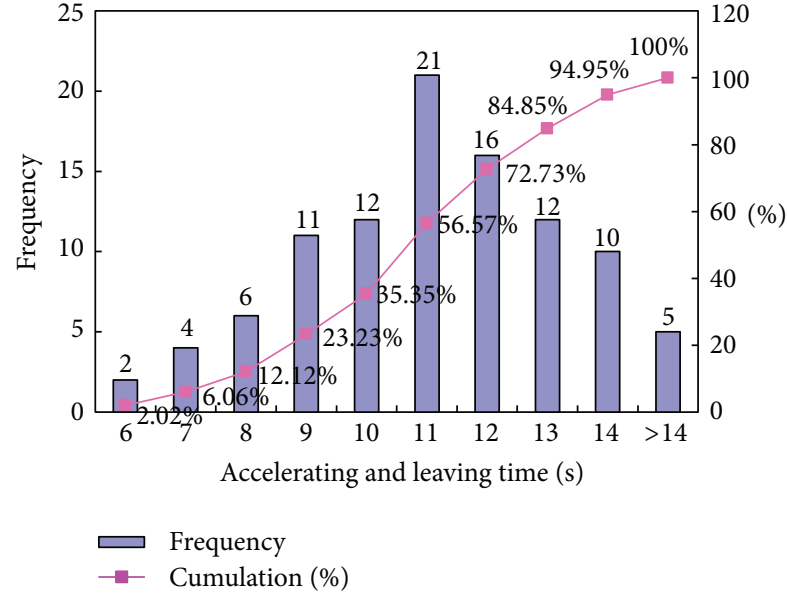

(b)

FIgURE 4: Distribution of $T_{1}$ and $T_{3}$ of buses at bay-style stops.

TABLE 3: Results fitting the relationship between $T_{a \& b}$ and LF.

\begin{tabular}{lccc}
\hline Layout of bus stops & Fitting formations & Fitting equations & $R$-square \\
\hline \multirow{2}{*}{ Curbside stops } & Binomial distribution & $T_{a \& b}=3.234 \mathrm{LF}^{2}-0.842 \mathrm{LF}+1.944$ & 0.833 \\
& Exponential distribution & $T_{a \& b}=1.762 \exp (0.4611 \mathrm{LF})+0.002496 \exp (7.152 \mathrm{LF})$ & 0.8619 \\
Bay-style stops & Binomial distribution & $T_{a \& b}=5.417 \mathrm{LF}^{2}-3.552 \mathrm{LF}+2.55$ & 0.8385 \\
& Exponential distribution & $T_{a \& b}=2.096 \exp (-0.1121 \mathrm{LF})+0.008578 \exp (6.12 \mathrm{LF})$ & 0.8804 \\
\hline
\end{tabular}

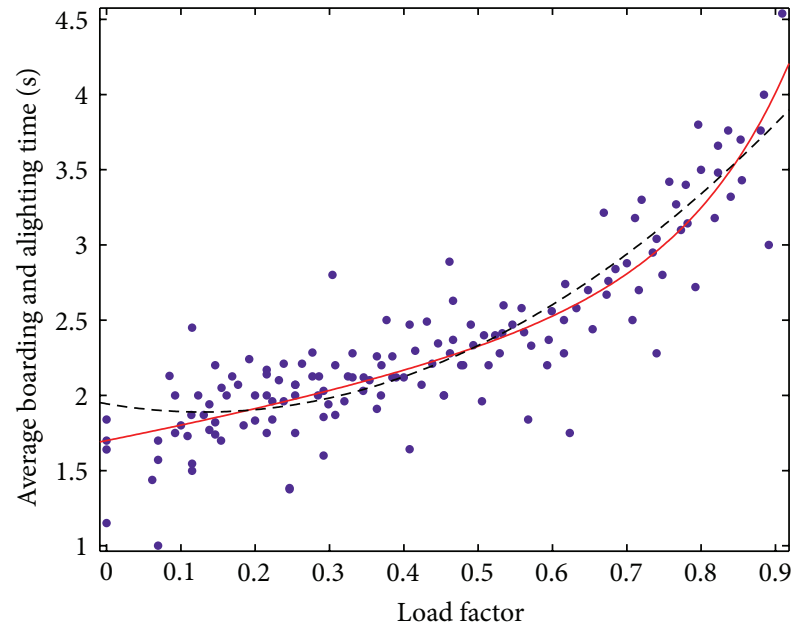

- Average time versus load factor

— Exponential fit

- - - Quadratic polynomial

FIGURE 5: Relationship between $T_{a \& b}$ and LF during buses in curbside stops.

According to the analysis before, delay calculations at bus stops are proposed in (2)

$$
T_{\mathrm{cd}}=T_{\mathrm{cdt}}-T_{\text {edt }},
$$

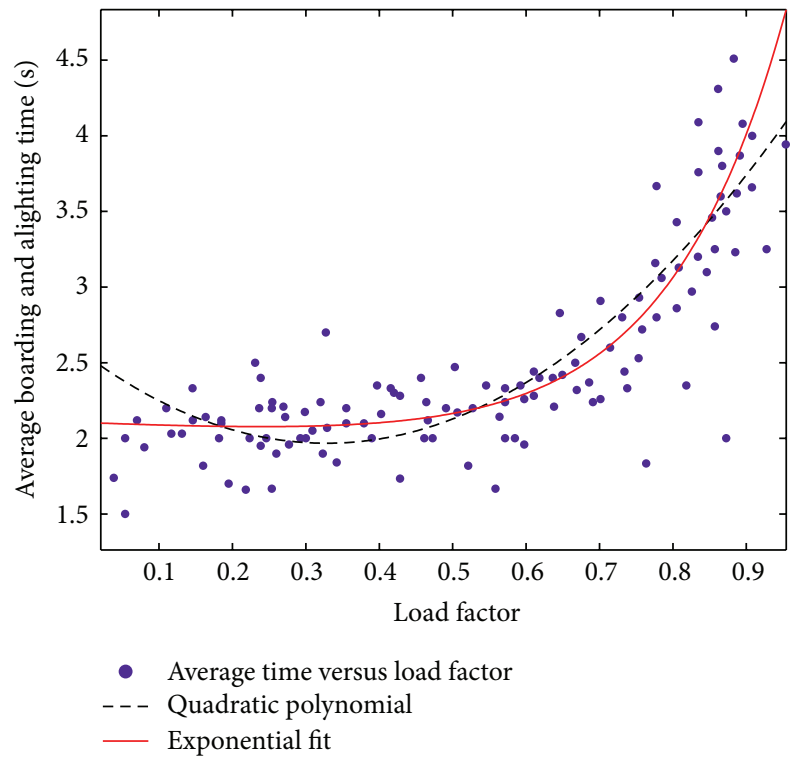

FIGURE 6: Relationship between $T_{a \& b}$ and LF during buses in baystyle stops.

where $T_{\text {cdt }}$ describes the calculated docking time of buses at stops and is given by (3) and (4) respectively for curbside and bay-style bus stops. Equations (3) and (4) should be calibrated for individual bus stops if field data could be obtained. $T_{\text {edt }}$ denotes the expected docking time of buses passing stops 


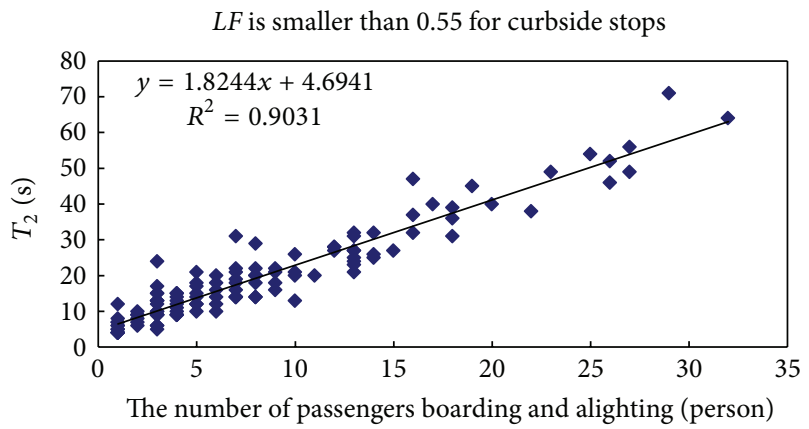

FIGURE 7: Relationship between the dwell time and number of passengers boarding and alighting at curbside stops when LF is smaller than 0.55 .

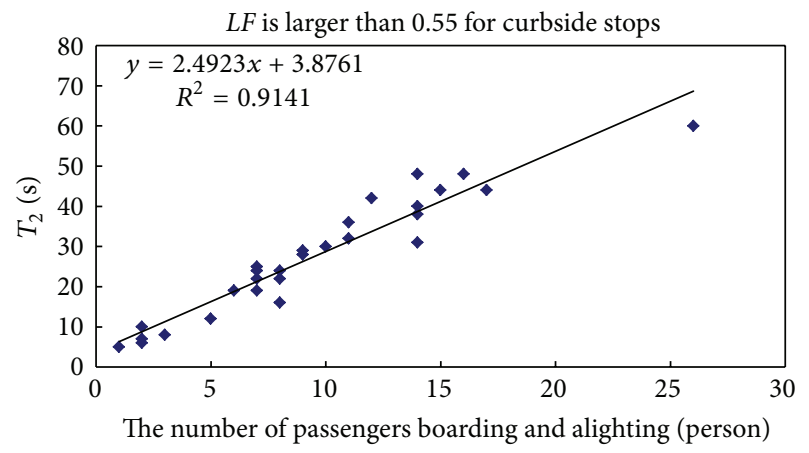

FIGURE 8: Relationship between the dwell time and number of passengers boarding and blighting at curbside stops when LF is larger than 0.55 .

without any delay. When approaching stops and passing the extended area as shown in Figure 2 at $10 \mathrm{~km} / \mathrm{h}$, buses spend seven seconds to finish this procedure. $T_{\text {edt }}$ can be calculated in (5) where the expected docking time per passenger is $1.21 \mathrm{~s}$ [8]

$$
\begin{aligned}
& T_{\mathrm{cdt}}=\left\{\begin{array}{ccc}
9.74+1.824 * \max \left\{m_{1}, m_{2}, m_{3}\right\} & \\
+4.694+10.2 & \mathrm{LF}<0.55 \\
9.74+2.492 * \max \left\{m_{1}, m_{2}, m_{3}\right\} & \\
+3.876+10.2 & \mathrm{LF} \geq 0.55
\end{array}\right. \\
& T_{\text {cdt }}=\left\{\begin{array}{cc}
10.11+2.219 * \max \left\{m_{1}, m_{2}, m_{3}\right\} & \\
+4.359+11.12 & \mathrm{LF}<0.7 \\
10.11+2.373 * \max \left\{m_{1}, m_{2}, m_{3}\right\} & \\
+3.001+11.12 & \mathrm{LF} \geq 0.7
\end{array}\right. \\
& T_{\text {edt }}=1.21 * \max \left\{m_{1}, m_{2}, m_{3}\right\}+7 .
\end{aligned}
$$

From the comparisons of (3), (4) and (5), arriving/leaving time and boarding/alighting time under real traffic conditions are more than those without any delay. The additional time expenditure is induced by the large proportions of queuing, hindered and waiting delay as shown in Table 2.

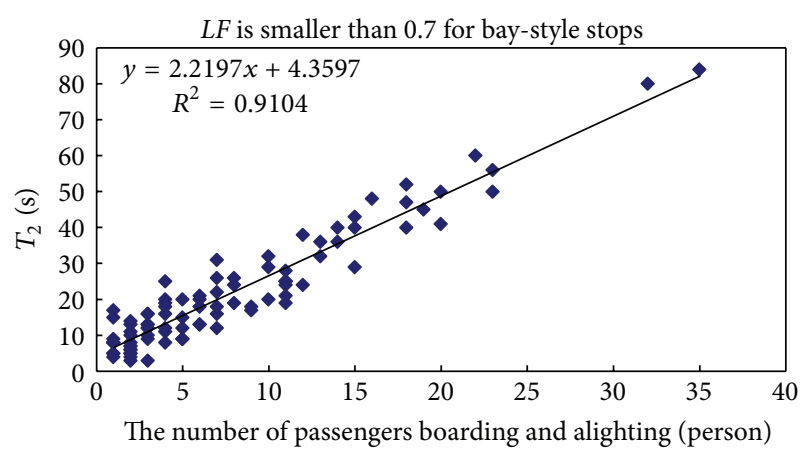

FIGURE 9: Relationship between the dwell time and number of passengers boarding and alighting at bay-style stops when LF is smaller than 0.7 .

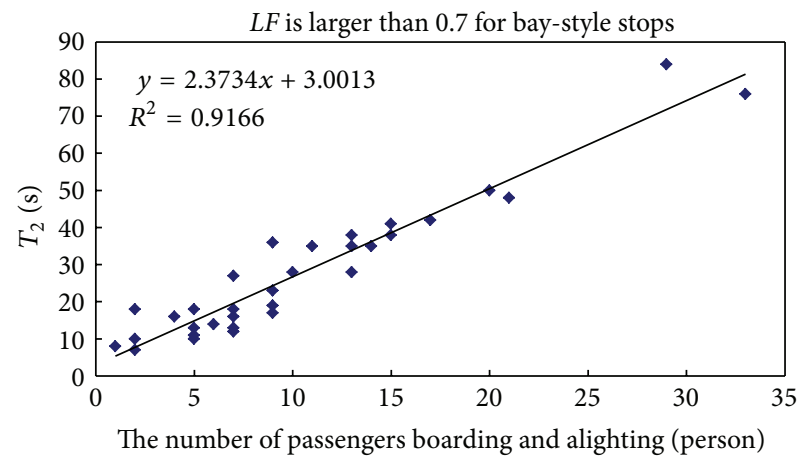

FIGURE 10: Relationship between the dwell time and number of passengers boarding and alighting at bay-style stops when LF is larger than 0.7 .

\section{Case Studies}

Three bus routes 105, 651 and 919 in Beijing are selected to calculate the bus delays at stops in case studies for validating the proposed method. Route 105 is a short distance route only about 12.86 kilometers, having 21 stops and mainly serving downtown traffic. Route 651 is a medium distance route about 27 kilometers, having 29 stops and serving those passengers plying between downtown and suburbs. Route 919 is a long distance route more than 83 kilometers, have 29 stops and serving those passengers travelling between downtown and rural area. The details, such as the layouts of bus stops and their numbers, passenger amount, travel time, actual docking time and delay as well as the calculation results, are listed from the second to thirteenth rows in Table 4.

The expected docking times (EDT) of three bus routes are calculated through (5) and given in the ninth row. EDTs are closely associated with the number of passengers boarding and alighting at stops and the number of bus stops. EDT of Route 651 is the largest among three routes as the numbers of its stops and passengers are both the largest.

The calculated delay $(\mathrm{CD})$ and docking time $(\mathrm{CDT})$ of three bus routes are obtained from (2) to (4). Actual bus delay is obtained as the difference between actual and expected docking times. The errors between calculated delay and actual delay of three routes are very tiny and less than $5 \%$. The 
TABLE 4: Calculation results of delay at bus stops along different bus lines.

\begin{tabular}{lcccc}
\hline \multicolumn{1}{c}{ No. of Route } & & 651 & 105 & 919 \\
\hline Number of curbside stops & $\mathrm{LF} \geq 0.55$ & 6 & 11 & 14 \\
& $\mathrm{LF}<0.55$ & 13 & 4 & 3 \\
Number of bay-style stops & $\mathrm{LF} \geq 0.7$ & 6 & 3 & 7 \\
& $\mathrm{LF}<0.7$ & 4 & 3 & 5 \\
Route length (km) & & 27.0 & 12.68 & 83.5 \\
Number of passengers (person) & 283 & 159 & 97 \\
Travel time (s) & 4988 & 3508 & 9332 \\
Expected docking time (s) & 538 & 339 & 320 \\
Calculated docking time (s) & 1432 & 1059 & 1072 \\
Actual docking time (s) & 1392 & 1050 & 1063 \\
Calculated delay (s) & 894 & 720 & 752 \\
Actual delay (s) & 854 & 711 & 743 \\
Error of delay calculation (\%) & 4.68 & 1.27 & 1.21 \\
Delay time/travel time (\%) & 17.1 & 20.3 & 8.0 \\
\hline
\end{tabular}

calculation errors of delay of Route 105 and 919 are even only $1.27 \%$ and $1.21 \%$. Such results show the proposed method can provide accurate calculation on delays at stops by data collections.

The proportions of delay time are also enumerated in the last row in Table 4. The delay proportions of Route 651 and 105 are more than $17 \%$ while that of Route 919 is just $8 \%$ as Route 919 serves more over the rural area where traffic nearly is unaffected by serious congestion in the downtown area. The average delays per stop of Route 651, 105 and 919 are respectively $29.4,33.9$ and 25.6 seconds at the similar level.

\section{Conclusions}

A calculation method on bus delay at stops which derive from queuing, hindering, waiting and second-stop is proposed in this paper based on the microscopic analysis of the procedure when buses pass their stops. The method considers the differences of bus layouts and passenger amount. The conclusions are helpful to planners and managers in the evaluation of bus operation through the case studies where the proposed method is employed based on the real data of three bus routes in Beijing.

First, queuing, hindered and waiting delay are the foremost three causes during the whole process of buses docking from the observed data.

Second, the arriving and leaving time of buses at bay-style stops is slightly larger than that of buses at curbside stops. Furthermore, the leaving time of buses from stops is larger than the arriving time approaching stops, no matter curbside or bay-style stops.

Third, the boarding and alighting time per passenger will greatly increase when the load factors of buses exceed 0.55 and 0.7 respectively at curbside and bay-style stops. The time under higher load factor is 1.47 times larger than that under lower one. Apparently, buses with large capacity are probably more favorable to reduce delay at stops in large cities.
Last, the calculation errors of bus delay along three routes are less than $5 \%$ in case studies by the proposed method. The proportion of bus delay within downtown area is larger than $17 \%$ while that over rural area is only about $8 \%$. The average delays per stop of these routes are larger than 25 seconds.

The further work is supposed to focus on the analysis of bus operational reliability and the evaluation on level of service of buses through combining the proposed method with advanced data collections, such as smart fare card and wireless communication tools. Moreover, the influence analysis on bus delay calculation from the differences of load factors between curbside and bay-style stops is also expected through special investigation and analysis.

\section{Acknowledgments}

The authors are grateful to the National High Technology Research and Development Program of China (2011AA110303), National Basic Research Program of China (2012CB725406) and National Natural Science Foundation of China (71001006) for its support on this work.

\section{References}

[1] Beijing Transportation Research Center, Beijing Transport Annual Report, Beijing, China, 2012.

[2] R. Fernandez and N. Tyler, "Effect of passenger-bus-traffic interactions on bus stop operations," Transportation Planning and Technology, vol. 28, no. 4, pp. 273-292, 2005.

[3] S. Jaiswal, J. Bunker, and L. Ferreira, "Influence of platform walking on brt station bus dwell time estimation: Australian analysis," Journal of Transportation Engineering, vol. 136, no. 12, pp. 1173-1179, 2010.

[4] P. G. Furth and J. L. SanClemente, "Near side, far side, uphill, downhill: impact of bus stop location on bus delay," Transportation Research Record, no. 1971, pp. 66-73, 2006.

[5] I. O. York, Factors Affecting Bus-Stop Times, Project Report/Transport Research Laboratory, Traffic and Transport Resource Centre, Crowthorne, UK, 1993.

[6] M. N. Milkovits, "Modeling the factors affecting bus stop dwell time-use of automatic passenger counting, automatic fare counting and automatic vehicle location data," Journal of the Transportation Research Board, no. 2072, pp. 125-130, 2008.

[7] E. Gonzalez, M. Romana, and O. Alvaro, Bus Dwell-Time Model at Main Urban Route Stops: A Case Study in Madrid-Span, Transportation Research Board Annual Meeting, National Research Council, Washington, DC, USA, 2012.

[8] Y. Wu and D. G. Xu, "The analysis of berthing time characteristics at the bus stop," Urban Public Transport, vol. 12, pp. 78-80, 2007.

[9] M. T. Li, F. Zhao, L. F. Chow, H. Zhang, and S. C. Li, "Simulation model for estimating bus dwell time by simultaneously considering numbers of disembarking and boarding passengers," Transportation Research Record, no. 1971, pp. 59-65, 2006.

[10] R. Fernández, P. Zegers, G. Weber, and N. Tyler, "Influence of platform height, door width, and fare collection on bus dwell time," Transportation Research Record, no. 2143, pp. 59-66, 2010.

[11] Z. Xu, A. V. Kwami, and X. K. Yang, "Bus delay factor analysis at and near the bus stop and an approach to delay estimation," Wuhan Ligong Daxue Xuebao, vol. 34, no. 5, pp. 877-881, 2010. 
[12] R. Rajbhandari, S. I. Chien, and J. R. Daniel, "Estimation of bus dwell times with automatic passenger counter information," Transportation Research Record, no. 1841, pp. 120-127, 2003.

[13] X. Wang, Statistic analysis of delay at urban transit station and its countermeasure [Ph.D. thesis], Chang'an University, Xian, China, 2007.

[14] H. Z. Aashtiani and H. Iravani, "Application of Dwell time functions in transit assignment model," Transportation Research Record, no. 1817, pp. 88-92, 2002.

[15] Z. Y. Mei, D. H. Wang, F. J. Wang, J. Chen, and W. Wang, "Research on the multiroute probit-based public transit assignment model based on bus stop," Mathematical Problems in Engineering, vol. 2012, Article ID 814036, 11 pages, 2012.

[16] B. R. Han, L. Lin, and X. Fan, "Survey and analysis of bus delay in bus stop," Urban Transport of China, vol. 2, no. 4, pp. 68-71, 2004.

[17] Z. H. Wei, X. Zhao, K. W. Wang, and Y. Xiong, "Bus dispatching interval optimization based on adaptive bacteria foraging algorithm," Mathematical Problems in Engineering, vol. 2012, Article ID 389086, 10 pages, 2012.

[18] J. Yang, Capacity calculation method of multi-line bus stop [Ph.D. thesis], Beijing Jiaotong University, Beijing, China, 2010. 


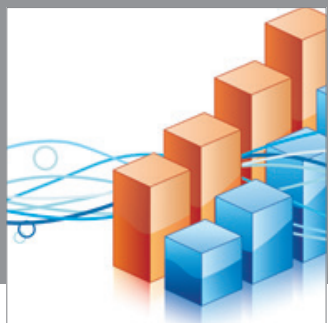

Advances in

Operations Research

mansans

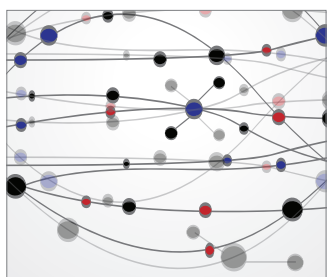

The Scientific World Journal
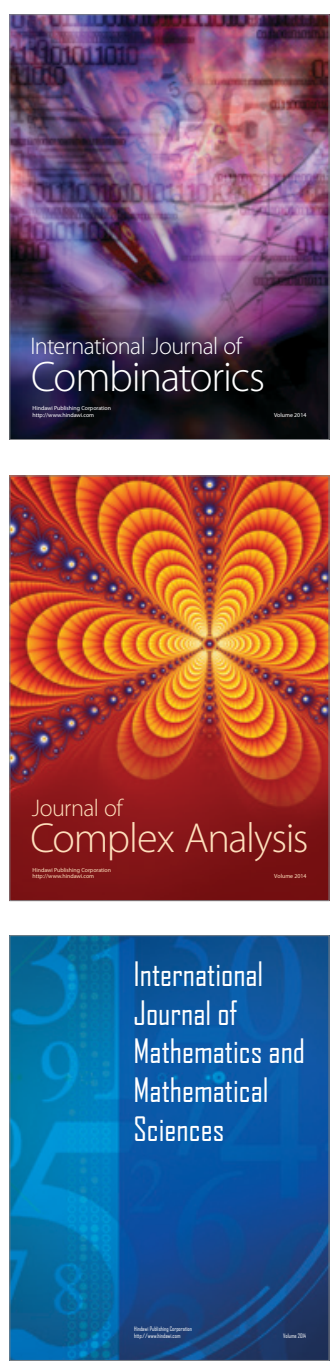
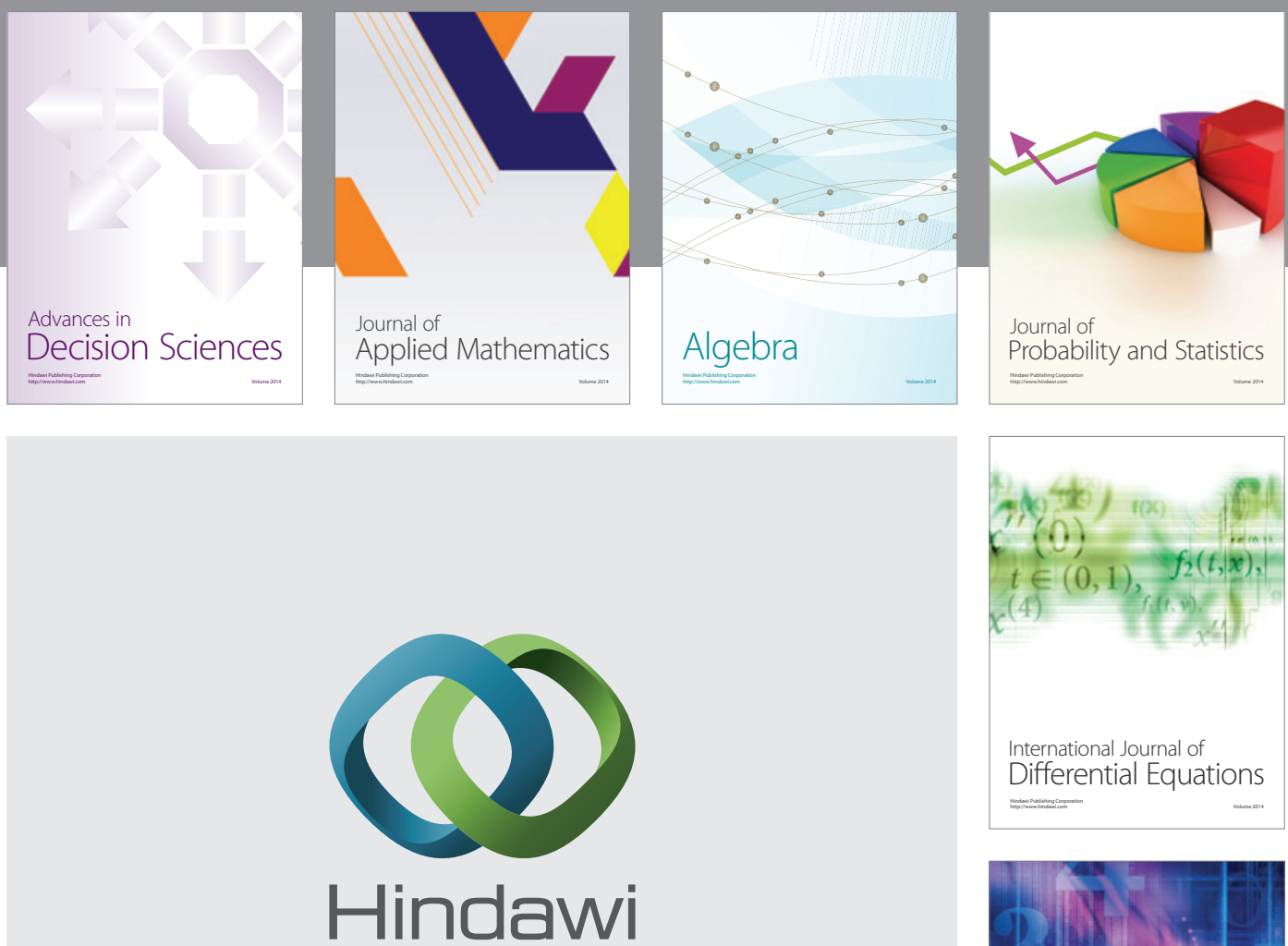

Submit your manuscripts at http://www.hindawi.com
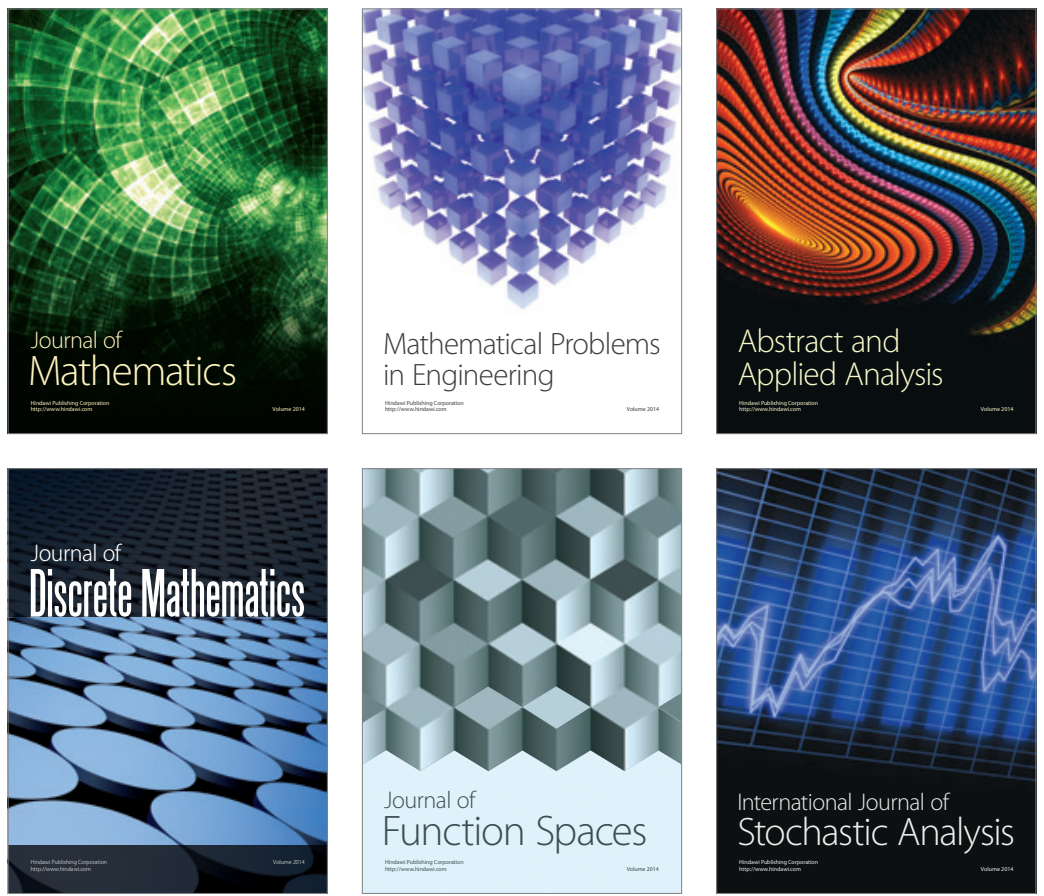

Journal of

Function Spaces

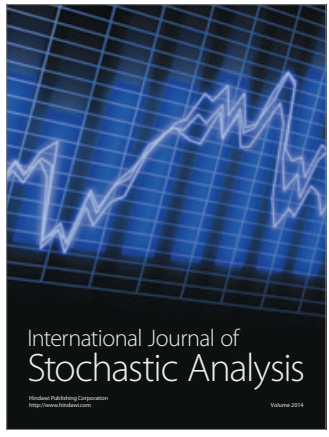

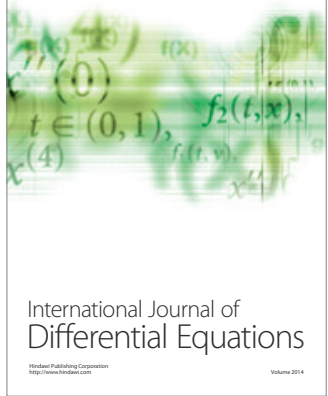
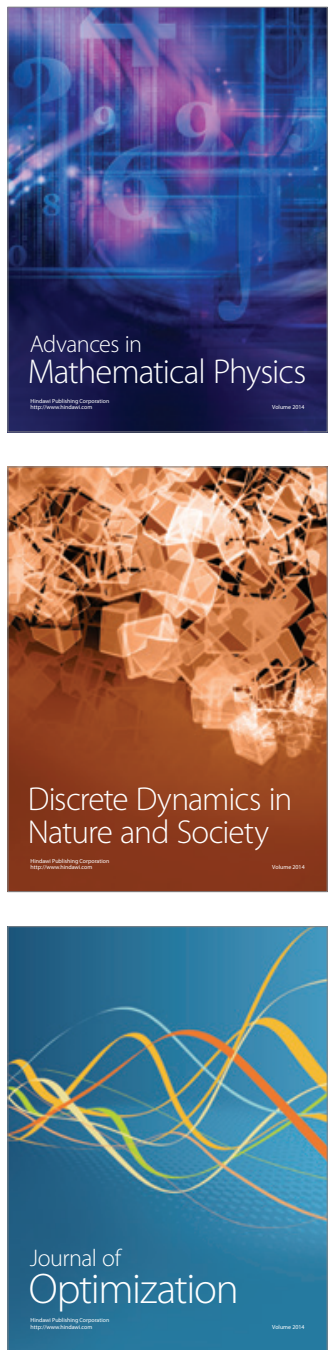